\title{
LA EXPANSIÓN DE LAS TIERRAS CULTIVADAS A LO LARGO DEL SIGLO XVIII. LOS ESTABLECIMIENTOS DEL CONDADO DE ELDA
}

\author{
Remedios Belando Carbonell
}

\begin{abstract}
El siglo XVIII supone, para el Reino de Valencia, una etapa de gran crecimiento demográfico, y aunque los distintos autores difieren en lo que respecta a su cuantificación, todos parecen coincidir en que fue, posiblemente, el más importante del conjunto peninsular ${ }^{1}$.

El Condado de Elda estaba integrado por los actuales municipios de Elda, Petrel y Salinas, en la comarca del Medio Vinalopó, formando parte, pues, de las tierras valencianas meridionales donde se alcanzaron índices de crecimiento muy elevados ${ }^{2}$. Esto último se ha comprobado para ciertos núcleos de población de la citada comarca ${ }^{3}$, pero faltan investigaciones sobre el tema para otros tan importantes como Petrel, Elda y Novelda ${ }^{4}$.

No obstante, el conocimiento parcial de algunos datos del Condado como los aportados por recuentos, vecindarios, censos ilustrados y evolución de bautismos del Archivo Parroquial de Elda, parecen indicar la tendencia a una recuperación del vacío dejado por el extrañamiento de los moriscos, a lo largo del siglo XVII. Con lo cual, el importante crecimiento del setecientos, confir-
\end{abstract}

1 Vid. BUSTELO Y GARCÍA DEL REAL, F.: «La població del País Valencià al segle XVIII», Recerques, n. ${ }^{\circ}$ 5, Esplugues de Llobregat, Ariel, 1975, pp. 73-96, y PÉREZ PUCHAL, P.: Geografía de la población valenciana, Valencia, l'Estel, 1976.

2 BURRIEL DE ORUETA, E.: «Crecimiento demográfico de las comarcas del País Valenciano en el siglo XVIII», Cuadernos de Geografía n. ${ }^{\circ}$ 21, Valencia, 1977, pp. 1-20.

3 BELANDO CARBONELL, R.: Estudio demográfico de Monóvar (siglos XVI-XX), Universidad de Alicante-C.A.P., Alicante, 1982.

4 Para Elda vid. RAMOS VIDAL, J. A.: «Aspectos demográficos de Elda (siglos XVI, XVII y XVIII)», Revista Alborada N. ${ }^{\circ}$ 23, Elda, 1977, sin paginar. 
mado por esas mismas fuentes, no tendría su origen en una fuerte despoblación inicial ni estaría tan íntimamente relacionado con el decreto de expulsión de 1609.

Partiendo, pues, de ese elevado incremento demográfico del siglo XVIII cabría preguntarnos si, de forma paralela, se produjo también, en el Condado, un proceso de roturaciones o de aumento de la superficie cultivada. La respuesta a este interrogante es el objetivo de nuestro trabajo.

Para ello, en primer lugar, hemos de hacer mención a la forma de tenencia de la tierra ${ }^{5}$.

Aquéllas que habían pertenecido a los moriscos fueron confiscadas a favor del titular del señorío y repartidas a los nuevos pobladores de acuerdo con las condiciones estipuladas en la Carta de Población de 1611-12. De ella emanan los «establiments» cuyo contenido desborda el marco de la mera enfiteusis alodial ${ }^{6}$.

Dejando aparte los aspectos jurisdiccionales, nos encontramos, por tanto, con unos contratos enfitéuticos donde se establecen unas relaciones de propiedad compartida entre el estabiliente, que conserva el dominio directo, y el nuevo poblador que pasará a poseer el dominio útil. Este segundo, transformado en enfiteuta, debía soportar una serie de cargas económicas que, prescindiendo de las regalias, eran fundamentalmente pechos y diezmos.

El pecho consistía en un censo anual y perpetuo, a percibir en moneda, proporcional al valor estimado de cada tipo de tierra. Por su carácter de renta fija en metálico el señor directo tenía garantizado su cobro independientemente del resultado de las cosechas; pero, asimismo, llevaba consigo el inconveniente de una desvalorización progresiva. Las tierras de natural no estaban sujetas al «pecho viejo» desde la Concordia de 1684.

En cuanto a los diezmos, como ocurría en otros señoríos limítrofes, el dueño del lugar era su único perceptor, suponiendo la octava parte de todos los frutos. Esto venía a compensar, en buena medida, la inexistencia de partición de frutos, y a él estaban sometidas todas las tierras, tanto de natural como de población ${ }^{7}$.

El sistema recaudatorio empleado era mediante el arrendamiento de los derechos dominicales y decimales. Una vez realizada la subasta para señalar

5 Para el estudio de la forma jurídica de explotación de la tierra en los señoríos valencianos es de obligada consulta el libro de GIL OLCINA, A.: La propiedad señorial en tierras valencianas, Ed. Del Cenia al Segura, Valencia, 1979.

6 La transcripción de la carta de población y de uno de los «establiments», junto a un comentario previo sobre su significado, se encuentra en SÁNCHEZ RECIO, G.: Carta de Población del Señorío de Elda (1611-1612), Ayuntamiento de Elda, Alicante, 1979.

7 SÁNCHEZ RECIO, G.: «Las rentas señoriales del Condado de Elda a finales del Antiguo Régimen. Los

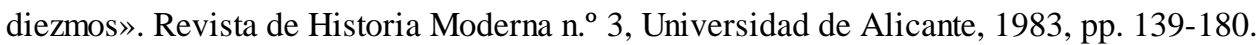


su cuantía eran adjudicados al mejor postor, a quien se otorgaba la consiguiente escritura.

El acceso a este tipo de documentos nos ha permitido establecer una evolución de los arrendamientos, sobre todo a lo largo de la segunda mitad del siglo XVIII, en lo que se refiere a las cantidades estipuladas, pues aunque la duración de los contratos era de 4 ó 6 años, aquéllas se pagaban anualmente ${ }^{8}$.

\section{CUADRO I}

Arrendamientos del Condado de Elda

\begin{tabular}{cc}
\hline$\underline{\text { Ano }}$ & $\underline{\text { Valor en libras (anual) }}$ \\
1725 & $3.900^{*}$ \\
1752 & 10.100 \\
1757 & 9.300 \\
1766 & 11.500 \\
1772 & 14.510 \\
1784 & 15.000 \\
1799 & 21.700 \\
\hline
\end{tabular}

Fuente: Archivo de Protocolos de Monóvar

* En 1725 el arrendamiento corresponde sólo a la villa de Elda. Ésta es la razón de un valor tan bajo.

Los datos expuestos indican una elevación importante en la cuantía de los arrendamientos a lo largo del setecientos, lo cual obedece a una serie de causas. Alza de precios de los productos agrícolas, expansión demográfica y extensión de las tierras cultivadas son, a nuestro parecer, primordiales.

La tendencia alcista de los precios tuvo una clara incidencia en el aumento de los ingresos del titular del señorío, concretamente en lo relativo a la percepción de diezmos. Esta se convierte en la partida más importante ante la carencia de partición de frutos y la desvalorización progresiva de los pechos. A su vez el alza de precios, junto al mayor número de usuarios por el incremento de la población, repercutió en los montantes por regalías, que pasan a ser los más elevados después de la renta decimal'

8 (A)rchivo de (P)rotocolos de (M)onóvar.

Arrendamientos de los derechos dominicales y decimales del Condado de Elda.

Año 1752: Joseph Ferrándiz Carratalá, 1752-61, Fol. 14-17v.

Año 1757: Pedro León Vidal, 1757-58, Fol. 39-44.

Año 1766: Pedro León Vidal, 1765-67, Fol. 45-54v.

Año 1772: Pedro León Vidal, 1770-72, Fol. 99v-110.

Año 1785: Gerónimo Amat y Planelles 1791-92, Fol. 30-32v. (cuentas).

Año 1799: Juan Amat y Amat, 1798-1800, Fol. 46v.-47v. (subarriendo).

Para 1725 vid. GIL OLCINA, A., op. cit., pp. 248-253.

9 GIL OLCINA, A., op. cit., pp. 96 y 97. 
El aumento de la superficie cultivada fue también un hecho paralelo al empuje demográfico del siglo, según se aprecia en los cuadros II, III, y V, (vid. apéndice estadístico) confeccionados a partir de los establecimientos de tierras efectuados a lo largo de la centuria ${ }^{10}$.

El procedimiento empleado para la puesta en cultivo de nuevas superficies incluía un permiso previo del Conde como dueño territorial. En caso afirmativo se dejaba constancia de ello en un contrato que contenía las condiciones a que quedaban sujetas las nuevas explotaciones. (Vid. apéndice documental).

Su análisis nos ha permitido conocer, en primer lugar, el número de establecimientos y la superficie que ellos incluyen. Transformando esta última en Ha. obtendríamos las cifras siguientes:

\begin{tabular}{lcccc} 
Municipio & $\begin{array}{c}\text { Superficie } \\
\text { actual (Ha.) }\end{array}$ & $\begin{array}{c}\text { Número de } \\
\text { Establecimientos }\end{array}$ & $\begin{array}{c}\text { Superficie que } \\
\text { ocupan(Ha.) }\end{array}$ & $\begin{array}{c}\text { \% respecto a } \\
\text { superficie actual }\end{array}$ \\
\cline { 2 - 3 } Elda & 4.470 & 20 & 67,37 & 1,51 \\
Petrel & 10.430 & 33 & 118,05 & 1,13 \\
Salinas & 6.190 & 68 & 450,07 & 7,27 \\
Total & 21.090 & 121 & 635,49 & 3,01
\end{tabular}

* En algunos ya hemos reseñado que no consta la extensión. Equivalencias: 1 jornal $=4$ tahúllas.

1 tahúlla $=1.138 \mathrm{~m}^{2}$ en Elda y Salinas, y $1.201 \mathrm{~m}^{2}$ en Petrel.

Es evidente que el más afectado por las roturaciones del siglo XVIII fue el entonces lugar de Salinas, que partía de un mayor vacío poblacional que Petrel y Elda mientras su término era bastante más extenso que el de esta última. A finales de siglo Cavanilles se percata de todo ello cuando afirma: «...Todo el término es capaz de muchas mejoras pero faltan brazos...», palabras empleadas en la descripción de Salinas, y «...tiene apenas una hora de diámetro, corto a la verdad para los 1.000 vecinos de la villa...», cuando se refiere a Elda ${ }^{11}$. El mismo autor considera que la escasez de población en Salinas se debe a los efectos perniciosos de su laguna, y en este sentido hay que destacar

10 Para conocer el total de establecimientos de tierras del Condado se han manejado casi todos los libros de Protocolos de Elda y Petrel, correspondientes al siglo XVIII, que se hallan en el Archivo Notarial de Monóvar. El deplorable estado de conservación de alguno de ellos no ha hecho posible su consulta.

11 CAVANILLES, A. J.: Observaciones sobre la Historia Natural, Geografía, Agricultura, Población y Frutos del Reyno de Valencia, Madrid, 1795-97, Zaragoza, 1958, Vol. II, pp. 260 y 258. 
que no todos los establecimientos se hacen a vecinos del lugar, ni siquiera del Condado, sino a otros de pueblos limítrofes como el de $\operatorname{Sax}^{12}$.

Siguiendo la evolución de concesiones a lo largo del siglo vemos como el máximo se alcanza en la década de los cuarenta, tanto en cada municipio como en el conjunto del señorío, con 65 de los 121 establecimientos y 762 jornales y 11 tahúllas de los 1.373'5 y 36 respectivamente que corresponden a toda la centuria. Al menos para la villa de Elda son, asimismo, los años en que los datos de bautismos parecen indicar un mayor despegue de la población ${ }^{13}$.

En segundo lugar estos contratos nos permiten conocer el régimen de tenencia que adoptan los nuevos establecimientos.

Fue norma generalizada en todo el País Valenciano la imposición de condiciones similares a las contenidas en las cartas pueblas, y esto mismo ocurre en el Condado de Elda. Es también la razón de haber expuesto en líneas anteriores las cargas económicas a que estaban sometidos los titulares del dominio útil. Sin embargo, existen también algunas diferencias.

En este sentido es interesante reseñar que en los nuevos establecimientos todos debían pagar diezmo, pero sólo algunos estaban sujetos al pecho, en concreto 23,7 y 13 en Salinas, Petrel y Elda respectivamente. Y ha llamado nuestra atención el que la exención del censo en metálico sea un hecho más generalizado en los años 40, década a la que, como ya se ha visto, corresponde el mayor número de roturaciones. En cualquier caso era la renta decimal la que aportaba más numerario a las arcas de la Señoría, aun en el supuesto de que fuera menor la proporción a satisfacer por este tributo ${ }^{14}$. Prueba del aumento de esta partida es también la Concordia de 1769 entre el Conde y D. José Tormo, Obispo de Orihuela ${ }^{15}$.

Otra de las diferencias estribaría en el plazo de uno o varios años que ahora se concede al enfiteuta para poner en cultivo las tierras establecidas. No hay que olvidar, sin embargo, que los trabajos conducentes a este fin corrían totalmente a cargo del colono y que, según el tipo de suelos, podían exigir esfuerzos considerables. A este respecto resulta ilustrativo la localización de algunas de las partidas rurales donde se ubican estos nuevos establecimientos

12 Vid. (A)rchivo (M)unicipal de (S)alinas. Legajo 1. ${ }^{\circ}$ : Actas Municipales 1741-98. Sin foliar. Día 6-11-1747. En este informe del Ayuntamiento se dice que Salinas tiene un total de 80 vecinos, ya que, «aunque el término éste parece algo dilatado, la mayor parte la poseen terratenientes...».

13 RAMOS VIDAL, J. A., op. cit.

14 Concordia de 1727 entre el Conde y la villa de Petrel. A.P.M. Notario Gerónimo Amat, 1726-1731. El diezmo de los granos de trigo, cebada, avena y centeno queda reducido al décimo para sus vasallos de Petrel.

También en el citado archivo, vid. Protocolos de Pedro León Vidal. 1759-61: Concordia entre el Conde y el lugar de Salinas. Según esta concordia se paga el décimo de todos los frutos y hortalizas, a excepción del panizo que diezma la octava parte.

15 Archivo Municipal de Elda. Varios papeles interesantes al pueblo de Elda desde 1771 a 1772. Concordia entre el Conde de Elda y el Obispo de Orihuela, pp. 1-12. 
(vid. mapa). Se ha escogido el mapa de Salinas por considerar que se trata del más representativo, pero antes de centrarnos en él hemos de precisar algunas cuestiones referentes a los otros dos municipios del Condado.

\section{CUADRO IV}

Distribución de establecimientos por partidas rurales (Término de Elda)

$\begin{array}{lcc}\text { Partida } & \text { Jornales } & \frac{N^{\circ} \text { establecimientos }}{4} \\ \text { Petiosa } & 46,5 & 3 \\ \text { Cañadas } & 35,0 & 6(2 \text { sin ext. }) \\ \text { Torreta } & 24,0 & 1 \\ \text { Salinetas } & 15,0 & 2 \\ \text { Marín } & 13,0 & 3(1 \text { sin ext. }) \\ \text { Camara } & 12,0 & 1 \\ \text { Derramador } & 2,5 & 20\end{array}$

El cuadro VI nos muestra el reparto de los establecimientos en el término de Elda. En este caso se ha podido confeccionar por ser aquél de reducidas dimensiones y, por consiguiente, estar concentradas las concesiones en muy pocas partidas. No obstante la de Salinetas pensamos que pertenece a Petrel, y no hemos podido localizar la Petiosa aunque posiblemente corresponda a la zona de Camara. Precisamente en esta última se sitúa un establecimiento de 1771 que nos puede dar idea de la escasez de tierras frente a una demanda que se hacía creciente por el aumento de los hombres. Se trata de un padre de 10 hijos que pide se le establezca un llano sin cultivar localizado en la senda que sube a la cumbre de Camara. La concesión no especifica la superficie y la carga se reduce al diezmo, pero con tres años de exención para su puesta en cultivo $^{16}$.

En cuanto a Petrel, se trata, como ya hemos visto, del término que ocupa la mayor superficie del Condado, y por ello los establecimientos están más dispersos; no obstante aparecen partidas rurales conocidas como son los casos de Navayol, Caprala y Figueralet.

Volviendo, pues, al caso de Salinas, en el mapa hemos situado aquellas partidas que, previamente localizadas, concentran el mayor número de rompimientos de tierras. Así tenemos, por ejemplo, de más a menos, La Fontana, con 120 jornales, La Herrada (S. ${ }^{a}$ de Salinas ?), con otros 120 jornales, La Umbría con 97, Cabrera con 81, Cabezo del Aguila con 75, Corral Blanco (?) con 64, Castillarejos (Castillejos?) con 42, Peñas Blancas con 40, el Collado

16 A.P.M. Notario Pedro León Vidal, 1770-1772. Año 1771, fol. 46. 


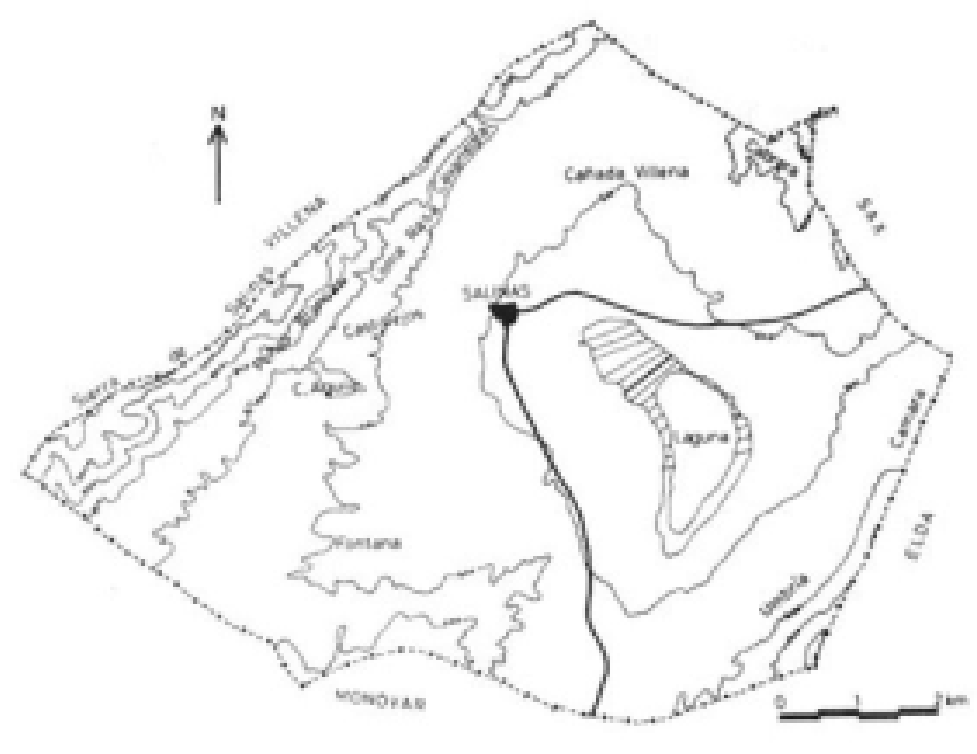

Salinas: Localización de alguna de las partidas rurales donde se ubican la mayor parte de los establecimientos del siglo XVIII.

de Monóvar con otros 40, Mojonera y Cañada de Villena con 25, Loma Rasa con 20, ademas del Barranco de Saladines, camino de la Cava Negra, etc...

En casi todas ellas las tierras que se establecen figuran en los contratos con los adjetivos de secana, realenga, inculta, baldía, erial, u otros de esta naturaleza. Y por su situación en el

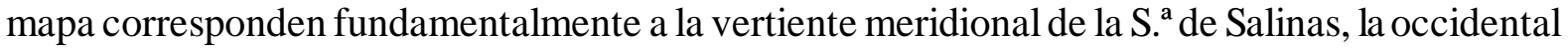
de Camara, sierra de Cabrera, y la de La Umbría, rebordes montañosos del municipio con amplias zonas de glacis que descienden hacia la parte deprimida donde se encuentra la laguna.

Hay también en Salinas un total de 17 establecimientos que suponen 34 jornales y 5 tahúllas y que constan como «tierra almarjal». Su superficie media es muy inferior a la del resto de concesiones del lugar, puesto que el mayor de ellos ocupa 5 jornales. Esa denominación, por su parte, nos está hablando 
de tierras situadas en la zona palustre que probablemente se dedicarían a la siembra de cereales $\mathrm{y}$ al cultivo de la barrilla ${ }^{17}$.

Finalmente hemos de hacer referencia al resto de imposiciones que figuran en los establecimientos del siglo XVIII. En definitiva, y aparte de lo ya expuesto, todo se reduce a las «...condiciones, capítulos y circunstancias prevenidas en los demás establecimientos antiguos de población...», con lo que estas tierras quedan asimiladas a las que el señor entregó a los nuevos colonos después del extrañamiento de la población morisca.

En respuesta al interrogante que quedó planteado en páginas anteriores, y que, como dijimos, constituía el objetivo de este trabajo, se ha de concluir afirmando que, efectivamente, durante el siglo XVIII, el Condado de Elda no sólo vio incrementar el número de sus hombres sino también la superficie ocupada por los espacios cultivados. Sin embargo Salinas presenta unas características especiales, porque aquí fue mucho más intenso el proceso de roturaciones que el crecimiento de su población. La mayoría de sus terratenientes, según el prólogo al Amillaramiento de 1818, eran vecinos de Monóvar, Sax y Villena, con lo que las tierras del lugar fueron colonizadas en su mayor parte por gentes que residían en municipios colindantes, aunque desbordando los límites del Condado e incluso del antiguo Reino de Valencia.

17 GIL OLCINA, A.: «Explotación y cultivo de las plantas barrilleras en España», Estudios Geográficos, números 138-139, 1975, pp. 453-478. Según Gil Olcina era frecuente el cultivo asociado de barrilla con anís y cominos o con cereales. Estos últimos eran la cosecha principal de Salinas, pero también muchos campos se destinaban a los otros productos citados. A este respecto, vid. A.M.S., Legajo citado. Informe de 6-11-1747 y CAVANILLES, op. cit., pp. 260. 
APÉNDICE ESTADÍSTICO Y DOCUMENTAL 


\section{CUADRO II}

Establecimientos de tierras en el siglo XVIII (Elda)

\begin{tabular}{|c|c|c|c|}
\hline$A \tilde{n} o$ & Jornales & Tahúllas & Número \\
\hline 1742 & 44 & - & 4 \\
\hline 1746 & 5 & - & 1 \\
\hline 1748 & 4 & - & 1 \\
\hline 1754 & 2,5 & - & 1 \\
\hline 1755 & 45 & - & 3 \\
\hline 1771 & 24 & - & 3 (1 sin extensión) \\
\hline 1775 & 13 & - & 2 \\
\hline 1778 & 5 & - & 3 (2 sin extensión) \\
\hline 1787 & 3 & - & 1 \\
\hline 1792 & 2,5 & - & 1 \\
\hline Total & 148,0 & - & 20 ( 2 sin extensión) \\
\hline
\end{tabular}

Fuente: A. P. M. Elaboración propia.

\section{CUADRO III}

Establecimientos de tierras en el siglo XVIII (Petrel)

\begin{tabular}{|c|c|c|c|}
\hline Año & Jornales & Tahúllas & Número \\
\hline 1732 & - & - & 1 (1 sin extensión) \\
\hline 1735 & - & - & 4 (4 sin extensión) \\
\hline 1736 & 20 & - & 1 \\
\hline 1737 & 6 & - & 1 \\
\hline 1739 & - & 12 & 3 \\
\hline 1741 & - & - & 1 (1 sin extensión) \\
\hline 1742 & 30 & - & 1 \\
\hline 1743 & 71 & - & 7 \\
\hline 1744 & 16 & - & 2 \\
\hline 1745 & 71 & - & 4 \\
\hline 1746 & - & 8 & 3 (2 sin extensión) \\
\hline 1748 & - & 3 & 1 \\
\hline 1749 & 6 & - & 1 \\
\hline 1759 & 16 & 4 & 2 \\
\hline 1760 & 3 & - & 1 \\
\hline Total & 239 & 27 & 33 (8 sin extensión) \\
\hline
\end{tabular}

Fuente: A. P. M. Elaboración propia. 


\section{CUADRO IV}

Establecimientos de tierras en el siglo XVIII (Salinas)

\begin{tabular}{cccc} 
Año & Jornales & Tahúllas & Número \\
1736 & 16 & - & 3 \\
1738 & 2 & - & 1 \\
1739 & 22 & 3 & 5 \\
1740 & 17 & - & 3 \\
1741 & 212,5 & - & 12 \\
1742 & 156,5 & - & 13 \\
1743 & 59 & - & 6 \\
1744 & 38 & - & 3 \\
1745 & 32 & - & 2 \\
1751 & 12 & - & 1 \\
1754 & 65 & - & 2 \\
1755 & 50 & 4 & 2 \\
1756 & 12 & - & 1 \\
1764 & 80 & - & 2 \\
1765 & 4 & - & 1 \\
1767 & 1,5 & - & 1 \\
1769 & - & 2 & 1 \\
1771 & 75 & - & 3 \\
1772 & 30 & - & 1 \\
1777 & 34 & - & 2 \\
1778 & 8 & - & 1 \\
1787 & 10 & - & 1 \\
1793 & 50 & - & 1 \\
\hline Total & 986,5 & 9 & 68
\end{tabular}

Fuente: A. P. M. Elaboración propia. 


\section{CUADRO V}

Establecimientos de tierras en el siglo XVIII

(Condado de Elda)

\begin{tabular}{|c|c|c|c|}
\hline Año & Jornales & Tahúllas & Número \\
\hline 1732 & - & - & 1 (1 sin extensión) \\
\hline 1735 & - & - & 4 (4 sin extensión) \\
\hline 1736 & 36 & - & 4 \\
\hline 1737 & 6 & - & 1 \\
\hline 1738 & 2 & - & 1 \\
\hline 1739 & 22 & 15 & 8 (1 sin extensión) \\
\hline 1740 & 17 & - & 3 \\
\hline 1741 & 212,5 & - & 13 ( 1 sin extensión) \\
\hline 1742 & 230,5 & - & 18 \\
\hline 1743 & 130 & - & 13 \\
\hline 1744 & 54 & - & 5 \\
\hline 1745 & 103 & - & 6 \\
\hline 1746 & 5 & 8 & 4 (2 sin extensión) \\
\hline 1748 & 4 & 3 & 2 \\
\hline 1749 & 6 & - & 1 \\
\hline 1751 & 12 & - & 1 \\
\hline 1754 & 67,5 & - & 3 \\
\hline 1755 & 95 & 4 & 5 \\
\hline 1756 & 12 & - & 1 \\
\hline 1759 & 16 & 4 & 2 \\
\hline 1760 & 3 & - & 1 \\
\hline 1764 & 80 & - & 2 \\
\hline 1765 & 4 & - & 1 \\
\hline 1767 & 1,5 & - & 1 \\
\hline 1769 & - & 2 & 1 \\
\hline 1771 & 99 & - & 6 (1 sin extensión) \\
\hline 1772 & 30 & - & 1 \\
\hline 1775 & 13 & - & 2 \\
\hline 1777 & 34 & - & 2 \\
\hline 1778 & 13 & - & 4 ( 2 sin extensión) \\
\hline 1787 & 13 & - & 2 \\
\hline 1792 & 2,5 & - & 1 \\
\hline 1793 & 50 & - & 1 \\
\hline Total & $1.373,5$ & 36 & 121 (2 sin extensión) \\
\hline
\end{tabular}

Fuente: A. P. M. Elaboración propia. 


\title{
PETICIÓN AL CONDE DE ELDA PARA QUE CONCEDA EN ESTABLECIMIENTO UN PEDAZO DE TIERRA
}

\author{
Archivo Notarial de Monóvar. Protocolos de Pedro Navarro \\ y Barceló. 1777-1778. Año 1778, fols. 156 y 156v.
}

\begin{abstract}
Phelipe Bellot, vecino de la villa de Elda, con el respeto devido, ante el Señor Dn. Joseph Ayela, Procurador General del Excmo. Señor Conde de Puñonrostro, Elda y Anna, dueño de dicha villa, dice: Que en este término se encuentra un sitio de tierras de realengo incultas, partida de la Torreta, que linda con Pablo Bernabé, Juan Bernabé, Vicente Barberá y Thomas Bellot, que desea el suplicante panificar y poner corrientes; y respecto a que no puede efectuarlo sin el permiso del dicho Sr. Conde como a dueño territorial, recurre a V.M. como a su Procurador a fin se sirva mandar se le establezca dicho realengo, con el supuesto de obligarse el que suplica a escriturar en los términos que se le mande y obligarse a pagar el diezmo de los frutos que produjese dicha tierra, y aquel censo perpetuo que se considerase, con lo demás conveniente. Cuia gracia espera merecer de la justificación de V.M. Elda, 12 de Septiembre de 1778.

Elda, 16 de Septiembre de 1778.

Se le establece al suplicante el realengo que solicita con tal que escriture en forma de tener sugeta dicha tierra al dominio maior y directo del Excmo. Señor Conde de Puñonrrostro, dueño de esta villa, y al de sus succesores, pagando anualmente in perpetum seis dineros de censo a dicho Señorío, y sin perjuicio de las veredas para ganados y de otro tercero, debiendo panificar dicha tierra dentro del preciso término de dos años, bajo la pena de comiso. Y para que conste, lo firmo como a Procurador de dicho Sr. Excmo. Conde $=$ Ayela $=$.
\end{abstract}

\section{ESCRITURA DE UN ESTABLECIMIENTO DE TIERRAS EN EL CONDADO DE ELDA}

\author{
Archivo Notarial de Monóvar. Protocolos de Pedro Navarro \\ y Barceló. 1777-1778. Año 1778, fols. 155v.-158v.
}

En la villa de Elda, a diez y ocho días del mes de septiembre de mil setecientos setenta y ocho años. Ante mí el escribano y testigos bajo escritos fue presente el Dr. Dn. Joseph Ayela, Procurador General del Excmo. Sr. Conde de Puñonrostro, dueño de esta villa, de cuio extremo consta por los poderes que me exibió otorgados por su excelencia en Valencia, en primero de Septiembre del año pasado mil setecientos setenta y uno, autorizados por Pedro Milleras, escribano, que de ser bastantes para lo infraescrito yo el escribano doy fe. Y dixo: Que atendiendo a la súplica que le ha hecho Bonifacio Bellot de este vecindario, mediante memorial, para que le conceda en establecimiento un pedazo de realengo en este término, partida de la loma de la Torreta, 
que desea panificar, y linda con Pablo Bernabé, Vicente Barberá, Vicente Juan Segura y Phelipe Bellot, como consta mas por extenso por dicho memorial que va colocado en este protocolo y decreto a la letra del tenor siguiente:

Elda, 18 de Septiembre de 1778. Concédesele al suplicante el establecimiento que solicita sin perjuicio de tercero con tal que escriture en forma de tener dicha tierra sujeta al dominio mayor y directo del Excmo. Sr. Conde, dueño de esta villa, y a sus succesores, pagando anualmente seis dineros de censo perpetuo y panificando dicha tierra dentro del término de dos años bajo la pena de comiso, y para que conste, lo firmo $=$ Dr. Ayela $=$

Cuio decreto va conforme con su original, al que me remito, en cuia virtud y usando de sus facultades, por la presente otorga que esteblece y da en enphiteusis perpetuo al dicho Bonifacio Bellot y a los suyos dicho realengo, bajo los linderos que van expresados en la partida de la loma de la Torreta que mira hacia esta población con tal que deba tener dicha tierra sujeta al dominio mayor y directo del Excmo. Sr. Conde, dueño de esta villa, pagando anualmente in perpetum seis dineros de pecho y el diezmo que produjese la referida tierra, la que debe panificar y cultivar dentro el término de dos años bajo la pena de comiso, entendiéndose sin perjuicio de tercero, prometiendo le será estable y firme dicho establecimiento, sirviéndole de título esta escritura a dicho Bellot y los suyos para su uso, disfrute y posesión. Y presente siendo el nombrado Bonifacio Bellot inteligenciado del contexto de esta escritura, dixo la aceptada en toda forma, y se obligó a cumplir con su tenor y serie, y recibiendo en establecimiento dicho realengo y panificarlo dentro el preciso término de dos años bajo la pena de comiso, y no cumpliéndolo como va referido se le apremie con esta escritura, y el juramento de quien fuere parte de que le releva sin otra prueba aunque por derecho se requiera. Y al cumplimiento de lo que a cada parte toca cumplir, obligaron esto es, el dicho Dn. Joseph Ayela las rentas de su principal, y el citado Bellot su persona y bienes habidos y por haber, y dieron poder respective a las justicias de su fuero para que a ello les apremien como por sentencia passada en cosa juzgada y consentida. Renunciaron las leyes, fueros y derechos de su favor con la general en forma, en cuio testimonio assí lo otorgaron firmó sólo el dicho Dn. Joseph Ayela y por el citado Bellot que dijo no saber lo firmó uno de los testigos, que lo fueron Francisco Agustín Coluchi y Joseph Amat y Rico de este vecindario, a los cuales y a dichos otorgante y aceptante, yo el escribano doy fe conozco.

\author{
Firmado \\ Dr. Joseph Ayela Francisco Agustín Coluchi
}

Ante mí

Pedro Navarro y Barceló 